\title{
Retração por terapia de sangria para flacidez tecidual e fatores de crescimento
}

\author{
Dr. Fabiano de Abreu Agrela Rodrigues ${ }^{1}$ \\ deabreu.fabiano@gmail.com \\ Daniela Oliveira Lopes ${ }^{2}$ \\ daniela.lopezz@hotmail.com
}

\section{RESUMO}

Retração por terapia de sangria para flacidez tecidual e fatores de crescimento

Palavras-chave: pele; retração de tecido; sangria; terapia de sangria; fator de crescimento, flacidez.

\section{Retraction by bleed therapy for tissue flaccidity and growth factors}

\author{
ABSTRACT \\ Bleeding therapy retraction for tissue flaccidity and growth factors
}

Keywords: skin; tissue retraction; bleeding; bleeding therapy; growth factor; sagging.

Artículo recibido: 02 enero 2022

Aceptado para publicación: 28 enero 2022

Correspondencia: deabreu.fabiano@gmail.com

Conflictos de Interés: Ninguna que declarar

\footnotetext{
${ }^{1} \mathrm{PhD}$, neurocientista, neuropsicólogo, mestre em psicanálise com pós graduação em antropologia, jornalista e especialista em nutrição clínica.

CPAH- Centro de Pesquisas e Análises Heráclito Rua Costinha, n95 4550-023 Sobrado e Bairros Aveiro, Castelo de Paiva PORTUGAL

${ }^{2}$ Graduada em Estética e Cosmetologia - Universidade Braz Cubas - Bragança Paulista (SP). Pós Graduada em Estética e Cosmética Intradérmicos e Subcutâneos, FAISP. Especialista em Cosmiatria Orgânica e Ortomolecular.

Presidente da SindEstética e da Sociedade Brasileira Estética e Cosmetologia. Pós Graduanda em Estética e Cosmetologia Avançada, UNIFESP - Universidade Federal de São Paulo. Residência em Intradermoterapia Estética T.A.E. Pesquisadora em Cosmetologia em prol do envelhecimento, curso integrado a UNICAMP - Universidade Estadual de Campinas
} 


\section{INTRODUÇÃO}

\subsection{Terapia de sangria}

As terapias de sangria são técnicas desenvolvidas desde 1500 a.c, onde iniciaram os procedimentos com sanguessugas. O objetivo era de tratar coágulos e cicatrizar feridas.

Com o passar do tempo, a técnica foi evoluindo até chegar nas ventosaterapias. O procedimento causa sangria na epiderme com aumento da oxigenação e vascularização na derme superficial. O objetivo é diminuir o acido lático e o estresse das terminações nervosas.

Somado a isto, vem a acupuntura auricular esistêmica que correspondente a ativação ou sedação de pontos específicos para tratar diversas disfunções, inclusive estéticas.

Atualmente, o avanço tecnológico trouxe diversas técnicas usando terapias de sangrias, sendo elas: jato de plasma, eletrocautério, microagulhamento manual, microagulhamento elétrico, intradermoterapia pressurizada.

Todas as técnicas intradérmicas por terapia de sangria, tem sua variante na profundidade alcançada no tecido, o mecanismo de ação entre todas é causar uma retração de tecido e afinamento da capa cornéa.

Com o uso das terapias intradérmicas associadas a mesclas de ativos contendo aminoácidos, fatores de crescimento notou-se uma aceleração da retração tecidual por afinamento do tecido x aceleração da produção de colágenos nos fibroblastos, oriundos de dois fatores: o aumento da circulação períferica e oxigenação celular x a própria gotícula de sangria sendo o veículo principal para absorção dos ativos via transcutânea.

\section{FATORES DE CRESCIMENTO}

Os fatores de crescimento são moléculas proteícas de alto peso molecular; acreditam que essas moléculas exerçam seus efeitos sobre a matriz dérmica através da penetração do folículo piloso e glândulas sudoríparas. (pós photo da Platina) ou na presença de feridas (sangrias / microagulhamento).

O presente estudo foi desenvolvido para avaliação tecidual de mesclas dos ativos deste artigo, sendo aplicado por terapia de sangria com ativação sudorípara e sem ativação sudorípara. 
Os promotores de penetração lipofilicos obtiveram uma estimulação Dupla: os queratinócitos estimulam os fibroblastos para sintetizar fatores de crescimento que por sua vez estimula a proliferação dos queratinócitos, resultando na ampliação da estimulação inicial.

Sinergicamente foram utilizados anti-oxidantes e um gel contendo 8 fatores de crescimento, associado com ácido L ascórbico e extrato orgânico de cimicifuga racemosa CNS, neste caso aplicações home care.

A mescla clínica com fatores de crescimento, citocinas, cafeína, bisabolol, ácido glicirrizico, HIALMEATO DE SODIO, a mescla com esses fatores de crescimento ,citocinas, peptídeos, antioxidantes e agentes despigmentadores obtiveram resultados com retração do tecido em $37 \%$ em mulheres com idade entre 35 e 52 anos.

Importante lembrar que o ser humano possui 19 tipos de moléculas de colágeno, o colágeno tipo 1 é o que mais tem na pele adulta $80 \%$ e o colágeno tipo 2 na pele do embrião.

A redução do colágeno na pele foto envelhecida ocorre tanto por aumento da degradação de colágeno pela ação das metaloproteinases( Kollagenase) quanto por diminuição da produção de colágeno pelos fibroblastos.

Essa interrupção na síntese de colágeno novo é ocasionada pela interação com a matriz extracelular alterada que exerce o mecanismo inibitório sobre o fibroblasto.

Como eliminar esse processo?

Os fatores de crescimento, são liberados pelo organismo após a terapia de sangria.

O microagulhamento de $2,5 \mathrm{~mm}$, utilizei a técnica exclusiva de minha autoria, mixpun. Os canais do tecido com sua matrix forçada pela terapia se fecharam após duas horas de terapia de sangria. Os pacientes utilizaram os produtos home care, veiculados em água, durante as 2 horas pós procedimento, para os pacientes de idade entre 45 a 52 anos foram utilizados em conjunto com a terapia, durante 72 horas, com intervalos de 6 horas, métodos físicos com aquecimento local, por infra vermelho longo.

Um dos efeitos fisiológicos da terapia de sangria é a: angiogênese.

\subsection{Técnicas de intradérmicas}

A intradermoterapia consiste na aplicação de medicamentos através de injeção na pele ou subcutâneo. O medicamento aplicado é escolhido pelo biomédico esteta de acordo com o objetivo do tratamento. Esta técnica tem origem na França e é realizada para 
introduzir alta concentração de determinados medicamentos no local de ação, aumentando o resultado desejado.

A técnica é indicada para tratamentos de celulite, gordura localizada, estrias, flacidez e desvitalização da pele da face, em homens e mulheres. Este é o tratamento mais recomendado pela Sociedade Brasileira de Biomedicina Estética (SBBME) para a perda de gorduras localizadas.

\section{o Jato de Plasma e Eletrocautério, quais as diferenças?}

O Eletrocautério e o chamado de Jato de Plasma, apesar da aplicação terapêutica ser a mesma, é relevante salientar a diferença entre as duas técnicas.

No eletrocautério a corrente elétrica é disparada diretamente na superfície gerando uma queimadura superficial controlada, dependendo da intensidade da corrente teremos uma indução inflamatória até a destruição das alterações cutâneas. A retração de pele causada pelo eletrocautério foi relatada em alguns artigos. Conforme Coimbra (2010), observou-se que tratando lesões nas pálpebras inferiores através da eletrocoagulação ocorria retração da pele perilesional. O resultado encontrado mostrou-se promissor, havendo diminuição importante da flacidez cutânea e das rítides na região, decorrentes provavelmente da retração da pele ocasionada pelo trauma tecidual.

O Jato de Plasma é um aparelho que emite um estado da matéria, o plasma. Este estado da matéria é altamente energético, podendo interagir com o tecido cutâneo de diferentes formas, dependendo da intensidade de energia depositada. Quando ela é baixa, como em varredura, ele apresenta uma atividade séptica interessante, sendo indicado na terapêutica da acne. Com o aumento do depósito de energia, gera-se uma resposta inflamatória que estimula a produção de colágeno combatendo a flacidez e rugas, bem indicado em protocolos de rejuvenescimento. Com grande carga de depósito pontual de energia, ele desenvolve ainda uma atividade ablativa, que pode chegar até o nível de carbonização de algumas formações cutâneas como acrocódons, nevos e xantelasmas. A pele que recebe essa alta carga energética apresenta retração e justifica sua indicação para a famosa blefaro não cirúrgica (Emmert et AL, 2017).

\subsection{Microagulhamento}

A prática teve começo na década de 90, como nome de "subcisão". Primeiramente apresentada por Orentreich, sua aplicação era induzir a produção de colágeno no 
tratamento de cicatrizes cutâneas e rugas. Como a técnica envolvia lesão, foi designada como TIC - Terapia de Indução de Colágeno (CIT - Colagen Induction Therapy). Na mesma década, o Congresso de Cirurgia Plástica e Reconstrutora em Madrid, na Espanha e o Congresso Internacional de Cirurgia Plástica e Estética em Paris, na França, concordaram e aderiram à técnica. Na altura, o cirurgião plástico Camirand (1997), relatou resultados em punturações feitas com uma pistola de tatuagem em duas pacientes que apresentavam cicatrizes faciais hipercrômicas, produzidas após um procedimento cirúrgico na face (facelifting). O objetivo foi de camuflar com tatuagem a cicatriz, com pigmentos da cor da pele. No entanto notou-se que a lesão causada pelas finas agulhas, desencadearam uma nova síntese de colágeno saudável. Mas somente em meados de 2000 que o cirurgião plástico sul-africano Dermond Fernands concebeu um aparelho apropriado para a indução de colágeno, constituído por um cilindro rolante cravejado de microagulhas. O novo designer possibilitava uma perfuração uniforme e rápida, além de permitir trabalhar em áreas maiores e com profundidades diferenciadas para cada região. Desta forma foi criado o Dermaroller, marca registrada e mais conhecida nos tratamentos de microagulhamento. A injúria provocada pelo microagulhamento, desencadeia através da perda da integridade do tecido, uma nova produção de fibras colágenas afim de reparar as fibras danificadas, a dissociação dos queratinócitos, a liberação de citocinas ativadas pelo sistema imune, geram uma vasodilatação no local da injúria, fazendo com que queratinócitos migrem para a região e reestabeleçam o tecido lesionado. (ALBANO, R.P.S., PEREIRA,L.P ., ASSIS, I.B, 2018)

Este processo pode ser levado a cabo usando um roller ou uma caneta de microagulhamento. No caso do roller, dermaroller ou rolo de microagulhamento, é um aparelho pequeno que tem a forma de um cilindro. A quantidade de agulhas que contem depende especificamente do seu uso. O roller pode conter de 190 a 1080 agulhas, com comprimento de $0,2 \mathrm{~mm}$ a $3 \mathrm{~mm}$ e $0,1 \mathrm{~mm}$ a $0,12 \mathrm{~mm}$ de diâmetro no ponto máximo de penetração. Na sua composição, o corpo do objeto é de polietileno e composto por agulhas de aço inoxidável e estéreis, as quais são posicionadas equilibradamente em fileiras.

No caso das canetas de microagulhamento, estas podem ser manuais ou elétricas e suas agulhas são descartáveis. Esta já é uma diferença em relação ao roller, em que o 
aparelho todo é descartado. A caneta elétrica, possibilita regular o tamanho das agulhas $(0,25 \mathrm{~mm}$ a $2 \mathrm{~mm})$. Neste caso, e usando este aparelho significa que ao trabalhar com um número maior de agulhas, se obtém um trauma mais homogêneo.

Como já referido, a caneta pode ser manual ou eletrica e, por essa razão têm técnicas de funcionamento diferentes. A caneta manual é usada de forma a serem produzidos movimentos ascendentes e descendentes sobre a pele. No caso da caneta elétrica, esta é deslizada sobre o local a ser trabalhado. O processo deve ser repetido diversas vezes sobre a mesma área, com movimentos circulares ou retilíneos, até se obter o aspeto de lesão desejado, sem necessidade de exercer uma pressão sobre a pele.

A caneta eletrica possui algumas vantagens na sua utilização pois o seu manuseamento é mais fácil e é mais eficiente no tratamento de áreas como nariz, ao redor dos olhos ou boca, que são áreas pequenas.

\subsection{Intradermoterapia pressurizada}

A intradermoterapia foi uma técnica primeiramente relatada por Pistor em 1958 e utilizada para procedimentos médicos, com aplicação de fármacos altamente diluídos, através de injeções intradérmicas para o tratamento de dores.

Pistor observou a eficácia do tratamento pela estimulação do tecido que recebem a punctura e administração dos fármacos. Esta terapia torna-se mais atrativa devido a sua ação local e não sistêmica com os medicamentos.

Intradermoterapia pressurizada consiste em um procedimento minimamente invasivo, baseado na aplicação de enzimas diretamente no local a ser tratado, feita por um aparelho de injeção sem agulhas. Esta técnica é utilizada para o tratamento da celulite, gordura localizada, estrias, cicatrizes, flacidez, papada, definição abdominal, alopécia e rejuvenescimento da pele da face e é indicada para ambos os sexos. O grande diferencial está nas distintas composições dos ativos, que devem ser prescritos pelo profissional, de acordo com o biótipo e necessidades de cada paciente. Esta técnica exclui o uso de agulhas e observa-se uma maior distribuição das enzimas aquando da sua aplicação.

\section{CONCLUSÃO}

É sabido que a preocupação com a aparência está cada vez mais na ordem do dia. Estas preocupações fazem com que o mercado estético esteja constantemente em mudança 
e aprimorando as suas técnicas na esperança de responder de forma cada vez mais eficaz aos problemas dos pacientes.

Por outro lado, este mercado tem a preocupação de possuir uma diversidade de tratamentos que podem abranger variados valores de forma a que todos possam ter acesso a alguma das técnicas.

Nos últimos tempos tem vinda a crescer a preocupação por obter resultados potencializados por meio da associação de técnicas e tecnologias, apostando na eficácia e evitando efeitos colaterais indesejados.

\section{REFERÊNCIAS}

ALBANO, R.P.S1 ., Pereira,L.P2 ., Assis, I.B. 2018. Microagulhamento - A Terapia Que Induz A Produção De Colágeno - Revisão De Literatura. Revista Saúde Em Foco - Edição No 10

Dal'Asta Coimbra, Daniel. Eletrocoagulação fracionada para o rejuvenescimento da região orbital inferior.Surgical \& Cosmetic Dermatology, vol. 2, núm. 3, julioseptiembre, 2010, pp. 233-236

Emmert et AL. Plasmamedizin in der Dermatologie. Disponível em:<https://dermatologie.med.unirostock.de/fileadmin/Kliniken/duk/Plasma_i n_der_Dermatologie.pdf> Acesso em 14 mar. 2021

RIBEIRO, C. Cosmetologia aplicada à dermoestética. 2 ed. São Paulo, SP: Pharmabooks, 2010

ROSSI, A.B.R.; VERGNANINI, A.L. Cellulite: a review. Journal European Academy of Dermatology Venereology, v. 14, p. 251-262, 2000

Sampaio \& Rivitti .Eletrocirurgia, Eletrocauterização, Eletrólise e Iontoforese. In: SampaioSAP \& Rivitti EA.Dermatologia. SP: Ed Artes Médicas; 200. p.10931100 